\title{
PENINGKATAN PRODUKTIVITAS PETANI TANAMAN KOPI PEMANFAATAN TEKNOLOGI MESIN PENGERING KOPI BAHAN BAKAR BRIKET SEBAGAI BAHAN BAKAR ALTERNATIF
}

\author{
Duwi Leksono Edy ${ }^{1)}$, Widiyanti ${ }^{2)}$, Erwin Komara Mindarta ${ }^{3)}$ \\ Prodi Pendidikan Teknik Mesin ${ }^{1,2}$, Pendidikan Teknik Otomotif ${ }^{3}$, \\ Fakultas Teknik, Universitas Negeri Malang \\ Email: duwi.leksono.ft@um.ac.id, widiyanti.ft@um.ac.id, erwin.ft@um.ac.id
}

\begin{abstract}
The purpose of this is to increase the productivity of coffee crop husbandman by utilizing appropriate technology that functions for drying coffee. The coffee dryer uses fuel in the form of charcoal which is produced from coffee skin waste which becomes environmental waste. With the application of appropriate technology, the community of coffee farmers can make the process of drying coffee quickly without requiring considerable time. Community service activities are carried out in Tirtoyudo Village, Tirtoyudo District, Malang Regency by applying a coffee dryer oven machine using briquette fuel. The results of community service activities are: (a) the fulfillment of environmentally friendly and inexpensive energy sources for the process of drying coffee for partners in particular and the people of Tirtoyudo Village in general through the use of coffee waste as briquette fuel; (b) the fulfillment of coffee dryer with briquette fuel energy for partners in Tirtoyudo Village so that the process of drying coffee beans is more effective and efficient; (c) availability of standardized packaging production equipment for ground coffee for partners in Tirtoyudo Village so that the quality and price of partner coffee powder can compete in the market; (d) online marketing so that production can reach exports for sales, and (d) the socio-economic activities of the Tirtoyudo Village community become more qualified through small business groups drying coffee beans and processing coffee grounds.
\end{abstract}

Keyword: Oven coffee, husbandman,

\begin{abstract}
ABSTRAK
Tujuan dari kegiatan ini adalah untuk meningkatkan produktivitas para peta tanaman kopi dengan pemanfaatan teknologi tepat guna yang berfungsi untuk mengeringkan kopi. Mesin pengering kopi menggunakan bahan bakar berupa arang yang diproduksi dari limbah kulit kopi yang menjadi limbah lingkungan. Dengan penerapan teknologi tepat guna ini masyarakat petani kopi dapat melakukan proses pengeringan kopi secara cepat dengan tidak memerlukan waktu yang cukup banyak. Kegiatan pengabdian kepda masyarakat di laksanakan di Desa Tirtoyudo Kecamatan Tirtoyudo Kabupaten Malang dengan mengaplikasikan mesin oven pengering kopi dengan menggunakan bahan bakar briket. Hasil dari kegiatan pengabdian pada masyarakat ini adalah: (a) terpenuhinya sumber energi yang ramah lingkungan dan murah untuk proses pengeringan kopi bagi mitra khususnya dan masyarakat Desa Tirtoyudo pada umumnya melalui pemanfaatan limbah kopi sebagai bahan bakar briket; (b) terpenuhinya alat pengering kopi dengan energi bahan bakar briket bagi mitra di Desa Tirtoyudo sehingga proses pengeringan biji kopi lebih efektif dan efisien; (c) tersedianya alat produksi pengemasan terstandar untuk kopi bubuk bagi mitra di Desa Tirtoyudo sehingga mutu dan harga kopi bubuk produksi mitra dapat bersaing di pasaran; (d) pemasaran secara online sehingga hasil produksi bisa mencapai ekspor untuk penjualannya, dan (d) aktivitas sosial ekonomi masyarakat Desa Tirtoyudo menjadi lebih berkualitas melalui kelompok usaha kecil pengeringan biji kopi dan pengolahan kopi bubuk.
\end{abstract}

Kata Kunci: Mesini Oven, Petani Kopi

Sarwahita : Jurnal Pengabdian Kepada Masyarakat Vol. 16 No. 2 Tahun 2019| 175 


\section{PENDAHULUAN}

Desa adalah kesatuan masyarakat hukum yang memiliki batas wilayah yang berwenang untuk mengatur dan mengurus urusan pemerintahan, kepentingan masyarakat setempat berdasarkan prakarsa masyarakat, hak asal usul, dan/atau hak tradisional yang diakui dan dihormati dalam system pemerintahan Negara Kesatuan Republik Indonesia (UU No 6, 2014)

Kehidupan masyarakat desa akan bergantung dengan ketetapan peraturan yang ada di desa yang telah di tetapkan oleh kepala desa yang mana peraturan ini sebelumnya setujui oleh masyarakat, dalam kehidupan bermasyarakat di desa, masyarakat akan di hadapkan dengan suatu program desa yang telah di bentuk oleh kepada desa demi meningkatkan ekonomi dan kesejahteraan masyarakat desa itu sendiri.

Dampak dari program desa dapat dilihat dari segi positifnya, seperti mampu meningkatkan sistem perekonomian masyarakat desa dan mampu meningkatkan perkembangan desa. Sedangkan dari segi negatifnya yakni program desa harus mendapatkan persetujuan dari BPD dan masyarakat, danjika dalam pelaksanaan program desa kurang sesuai dengan ketentuan yangtelah ditentukan maka akan mendapatkan suatu hasil kemerosotan perekonomian masyarkat desa (http// wikepdia, perkembangan desa sektor ekonomi, html.01-11-2014).

Pengembangan perekonomian masyarakat desa perlu adanya pemberdayaan perekonomian masyarakat desa melalui produk produk local.

Pemberdayaan ekonomi kerakyatan mengandung maksud pembangunan ekonomi sebagian besar masyarakat Indonesia sebagai agenda utama pembangunan nasional sehingga langkah-langkah yang nyata harus diupayakan agar pertumbuhan ekonomi rakyat berlangsung dengan cepat (Swasono dalam Rintuh, Cornelis dan Miar.2005, h.84)

Dengan adanya pemberdayaan ekonomi masyarakat maka diharapkan dapat meningkatkan kehidupan masyarakat kearah kehidupan yang lebih baik. Kehidupan yang lebih baik menurut Goulet (dalam Suryana, 2006, h.6) pada dasarnya meliputi: kebutuhan hidup, kebutuhan harga diri, kebutuhan kebebasan. Oleh karena itu, ahli ekonomi mengemukakan bahwa sasaran pemberdayaan ekonomi masyarakat yang minimal dan harus mengutamakan apa yang disebut keperluan mutlak, syarat minimum untuk mmenuhi kebutuhan pokok serta kebutuhan dasar.

Sementara masalah ekonomi lebih sering muncul karena ketidak mampuan keluarga tersebut dalam mendapatkan penghasilan untuk memenuhi kebutuhan sehari-hari. Pengaruh yang diakibatkan oleh masalah ini sangatlah beragam. Mulai dari ketidak mampuan orang tua untuk membiayai pendidikan anakanaknya, tidak mampu untuk memenuhi kebutuhan hidup sehari-hari mulai dari makanan bergizi, pakaian layak pakai dan juga rumah yang sehat dan higienis. Menurut Rachman (2001), pola konsumsi dan pengeluaran rumah tangga 
umumnya berbeda antara agroeko sistem, antar kelompok pendapatan, antar etnis, atau suku dan antar waktu. Struktur pola dan pengeluaran konsumsi merupakan salah satu indikator tingkat kesejahteraan rumah tangga. Dalam hal ini rumah tangga dengan pangsa pengeluaran pangan tertinggi tergolong rumah tangga dengan tingkat kesejahteraan rendah dibandingkan rumah tangga yang proporsi pengeluaran untuk pangannya rendah.

Seiring dengan perkembangan zaman banyak sekali kelompok kelompok masyarakat yang mendirikan sebuah kelompok dibidang pertanian, dengan tujuan untuk meningkatkan taraf perekonomian masyarakat kelompok tani dengan meningkatkan hasil pertanian.

Seperti halnya wilayah Tirtoyudo merupakan salah satu kecamatan yang terletak diwilayah Kabupaten Malang. Secara letak geografis kecamatan Tirtoyudo Wilayah yang memiliki jumlah penduduk yang tersebar diwilayah desa. Perekonomian masyarakat Desa Tirtoyudo memiliki mata pencaharian sebagai petani dan juga sebagai TKI. Jumlah masyarakat yang bekerja sebagai petani juga tidak sedikit mencapai 20.634 penduduk bermata pencaharian petani (http://tirtoyudo.malangkab.go.id/.).

Hasil produksi pertanian yang pokok dan menjadi unggulan adalah tanaman perkebunan kopi. Hasil produksi kopi dari desa Tirtoyudo merupakan hasil komoditas utama mata pencaharian para petani untuk meningkatkan taraf perekonomian. Hasil pertanian kopi dari desa tirtoyudo sudah cukup terkenal mulai dari dalam negeri sampai kemanca Negara. Kopi Robusta dan kopi arabika merupakan kopi yang dihasilkan dari pertanian Desa Tirtoyudo yang memiliki ciri khas tersendiri dari rasa-rasa kopi yang lain. Akan tetapi semakin banyaknya permintaan kopi dari konsumen, peningkatan hasil produksi kopi juga semakin besar. Hal ini mengakibatkan semakin tingginya antisipasi petani masyarakat untuk memproduksi kopi juga semakin besar.

Proses produksi kopi
memerlukan beberapa tahapan setelah proses panen dari perkebunan. Proses pengeringan biji kopi memerlukan rentan waktu yang cukup lama hingga mencapai 2 sampai 3 minggu dengan kondisi cuaca yang bagus, dengan tujuan untuk mengurangi kandungan air yang terdapat di dalam kopi. Kandungan air sendiri setelah proses penjemuran harus menjapai $12 \%$ supaya kopi bisa tahan lama dan pada saat penggorengan bisa cepat.

Penjemuran kopi secara manual dan membutuhkan waktu lama ini yang menjadi permasalahan petani dalam proses produksi. Permasalahan ini dikomunikasikan dengan perangkat desa dan pada petani kopi yang selama ini menjadi kendala dan belum terdapat penyelesaiannya.

\section{METODE PELAKSANAAN}

\section{A. Tempat dan Waktu}

Kegiatan pengabdian kepada masyarakat dengan desiminasi Teknologi Tepat Guna dilaksanakan di Desa Tirtoyudo, 
Kecamatan Tirtoyudo Kabupaten Malang Jawa Timur.

\section{B. Khalayak Sasaran}

Kegiatan desiminasi Teknologi Tepat Guna ini dengan melibatkan UMKM kelompok Tani Kopi "Husada Budaya Tani” Desa Tirtoyudo Kecamatan Tirtoyudo Kabupaten Malang.

\section{Metode}

Mesin pengering kopi dengan bahan bakar briket dari limbah kopi merupakan mesin yang bekerja secara otomatis yang memiliki kapasitas 100 $\mathrm{kg}$. Mesin ini berkerja dengan pemanas yang dihasilkan oleh panas bahan bakar briket.

Untuk menjawab permasalahan mitra dalam kegiatan ini mengenai teknologi proses pengeringan kopi dan pengolahan limbah kopi yang menjadi pokok utama dalam kegiatan ini. Metodologi yang digunakan dalam kegiatan ini adalah 1) Survey ke lokasi Kelompok Tani Kopi Sebagai Mitra: Survey ke Kelompok Tani Kopi sebagai mitra perlu dilakukan untuk mengetahui permasalahan yang dihadapi dalam proses produksi untuk memenuhi permintaan pasar. Hal ini sangat penting sekali karena setiap petani tentu memiliki permasalahan yang perlu penyelesaian untuk kelangsungan produksi, sehingga permasalahan yang ada dapat dipetakan dan dikelompokkan untuk mempermudah manajemen permasalahan secara menyeluruh. 2) Diskusi dengan Mitra untuk Mengetahui Masalah dan Kebutuhan: Diskusi diperlukan untuk mencari jalan keluar yang dianggap mudah baik bagi penyelenggaran kegiatan ini. Dari diskusi yang dilakukan oleh penyelenggara kegiatan dengan kelompok Petani Kopi dan Kepala Kelurahan Tirtoyudo Bapak Sueb selaku pengembang dan penanggung jawab Kelompok Tani Kopi, memunculkan beberapa permasalahan yang selama ini terjadi dan belum ada penyelesainnya. 3) Analisa Permasalahan dan Kebutuhan: Setelah diketahui permasalahan dan kebutuhan proses selanjutnya adalah menganalisa permasalahan dan kebutuhan yang dibutuhkan oleh mitra. Tim akan menganalisa dan memproses setiap permasalahan sehingga diperoleh solusi berupa mesin mesin pengering kopi dan mesin pengolah limbah kopi menjadi arang. 4) Menyediakan mesin pengering kopi dan pengolah limbah: Mesin ini bertujuan untuk meningkatkan proses produksi dan meringankan mitra dalam proses produksi. 5) Pelatihan kepada Mitra: Pelatihan ini bertujuan untuk memberikan penjelasan secara komplek cara pengoperasian mesin dalam proses produksi dan juga strategi pengeringan dan pengelolaah limbah sebagai bahan bakar alternative. 6) Produk Luaran: Produk luaran berupa mesin pengering kopi dan mesin pengolah limbah kopi menjadi arang yang digunakan sebagai bahan bakar alternatif. 7) Evaluasi dan Monitoring: Evaluasi diperlukan untuk memberikan pengarahan dan perbaikan bagi mitra untuk memperoleh hasil luaran yang maksimal. Sedangkan monitoring digunakan untuk memastikan hasil luaran yang diperoleh dapat diterapkan 
sehingga memberi manfaat yang besar bagi masyarakat.

\section{HASIL DAN PEMBAHASAN}

Proses pengeringan kopi yang selama ini dilakukan petani kopi secara manual dan konvensional. Pengeringan kopi ini membutuhkan waktu yang cukup lama.

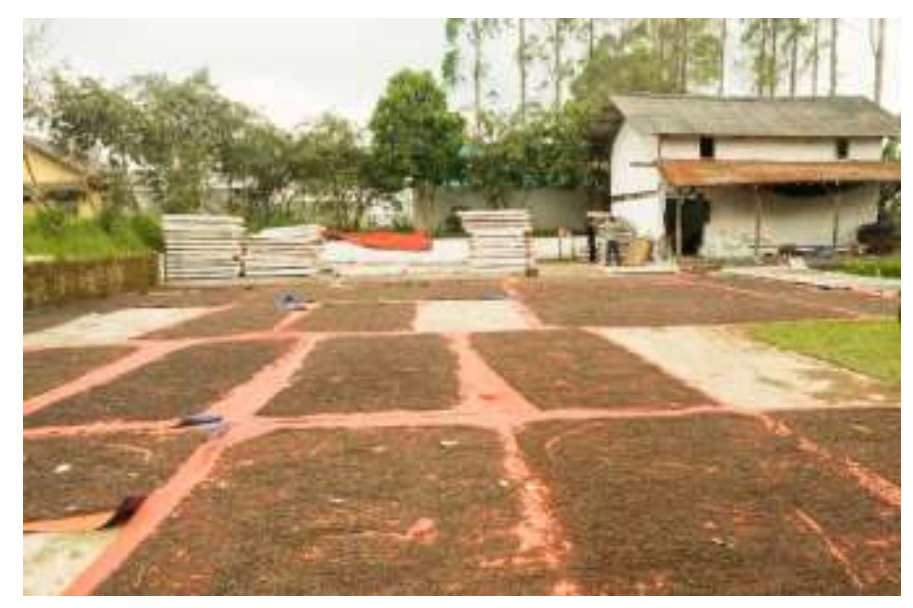

\section{Gambar 1. Penjemuran Manual Biji Kopi}

Penerapan teknologi tepat guna sangat diperlukan dalam proses produksi kopi dengan tujuan intuk mempercepat proses produksi. Teknologi yang diterapkan harus memenuhi lima kriteria, yaitu kelayakan agronomis, keuntungan yang akan diperoleh, kompatibilitas (kesesuaian) dengan sistem usaha tani (pola dan rotasi tanam, peralatan, dan sumber daya), kompabilitas dengan prasarana-sarana, ekonomi dan sosial masyarakat, dan dapat diterima secara social budaya (Van DerVeen and Gonzales 1997).

Tujuan pengembangan suatu teknologi pada dasarnya adalah untuk menjawab kebutuhan-kebutuhan, baik yang telah nyata, ataupun yang dirasakan dan diinginkan adanya, dan bahkan yang diantisipasi akan diinginkan, maka suatu upaya pengembangan teknologi yang efektif, pertama-tama harus didasarkan pada permintaan pasar, baik yang telah nyata ada, atau yang mulai tampak dirasakan adanya (Besari, M.S. 2008).

Penerapan Teknologi Tepat Guna diawali dengan pemahaman masalah dan peluang pengembangan sumber daya setempat. Tujuannya adalah mengumpulkan informasi dan menganalisis masalah, serta mengidentifikasi teknologi yang sesuai dengan kebutuhan petani di wilayah setempat. Uji teknologi di Balai Penelitian, sebelum teknologi dianjurkan biasanya terbatas pada uji keragaman hasil, analisis ekonomi secara umum, dan dampaknya terhadap pendapatan petani (Abdulrachman et al. 2006, Makarim et al. 2008).

Teknologi tepat guna sebagai salah satu jalur penting untuk mencapai tujuan yang mendasar, yakni meningkatkan kesejahteraan masyarakat. Sebagian 
besar masyarakat Indonesia dengan keanekaragaman ilmu pengetahuan dan teknologi (iptek) dapat diposisikan, tidak hanya sebagai pendukung, tapi juga sebagai pionir perambah jalan menuju terwujudnya masyarakat sejahtera berkeadilan bagi semua lapisan masyarakat di Indonesia yang berada di berbagai penjuru tanah air dengan tingkat kemampuan penguasaan teknologi dan ekonomi yang terbatas. Teknologi Tepat Guna berarti teknologi yang sesuai dengan kondisi budaya, dan kondisi ekonomi serta penggunaannya harus ramah lingkungan(

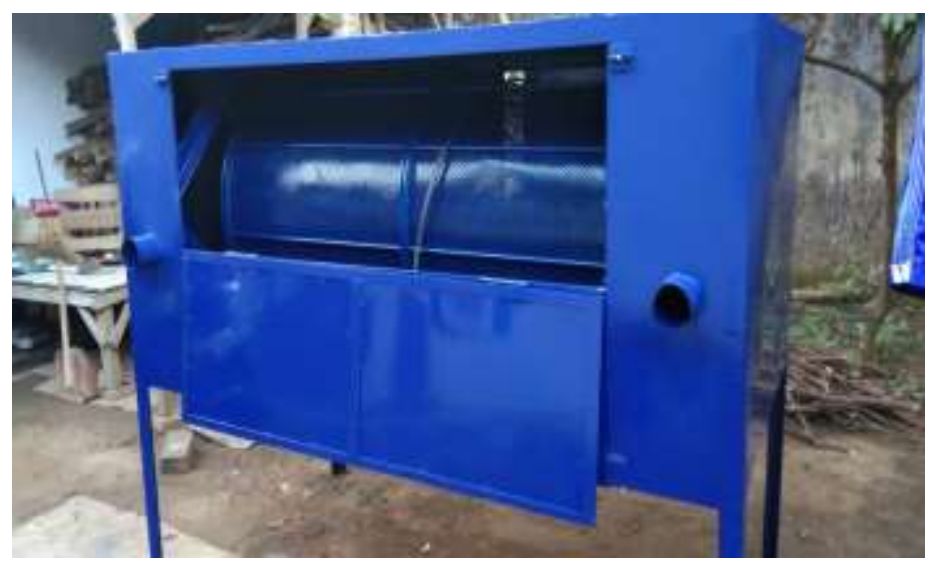

\section{Gambar 2. Mesin Oven Pengering Kopi}

Pelaksanaan kegiatan pengabdian pada masyarakat ini, dalam percepatan proses pengeringan kopi maka diterapkannya mesin oven untuk proses pengeringan kopi. Proses pengeringan kopi penggunakan bahan bakar yang multifungsi bias menggunakan gas, kayu, briket yang bisa dijadikan bahan bakar. Proses pengeringan kopi dengan penggunaan mesin oven memiliki tingkan pengeringan secara efisien, dengan proses pengeringan yang lebih cepat. Proses pengeringan yang dilakukan dengan cara konvensional memerlukan waktu 7 hari, dengan penggunaan mesin oven pengeringan dapat dilakukan dengan waktu 6 jam kopi sudah mengalami pengeringan.

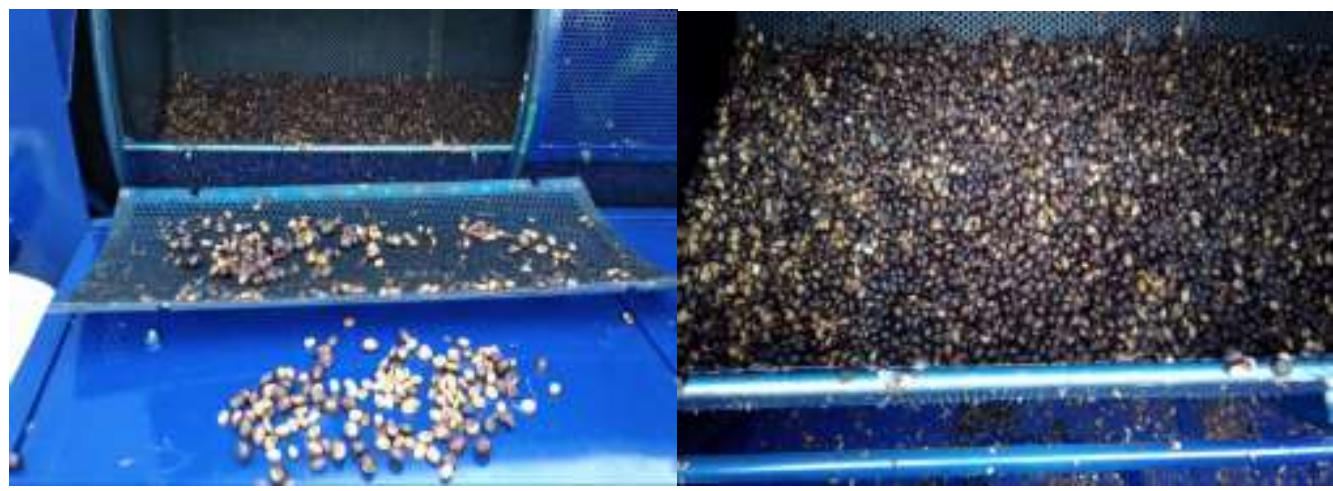

Gambar 3. Hasil Pengeringan Kopi 
Tabel 1. Peningkatan Produktivitas Masyarakat.

\begin{tabular}{|c|c|c|c|}
\hline No & Kegiatan & $\begin{array}{l}\text { Sebelum Kegiatan } \\
\text { Pengabdian }\end{array}$ & $\begin{array}{l}\text { Sesudah kegiatan } \\
\text { Pengabdian }\end{array}$ \\
\hline 1 & $\begin{array}{l}\text { Proses produksi } \\
\text { pengeringan kopi }\end{array}$ & $\begin{array}{l}\text { Pengeringan secara } \\
\text { Konvensional lama } \\
\text { Pengeringan max } 6 \text { hari }\end{array}$ & $\begin{array}{l}\text { Pengeringan dengan } \\
\text { menggunakan mesin oven } \\
\text { lama pengeringan } 3 \text { jam }\end{array}$ \\
\hline 2 & $\begin{array}{l}\text { Proses penjualan hasil } \\
\text { petani kopi }\end{array}$ & $\begin{array}{l}\text { Hasil pertanian kopi } \\
\text { langsung dijual ke suplyer }\end{array}$ & $\begin{array}{l}\text { Masyarakat melakukan } \\
\text { penjualan online melalui } \\
\text { E-Commerce. }\end{array}$ \\
\hline 3 & $\begin{array}{l}\text { Penggunaan teknologi } \\
\text { dalam masyarakat }\end{array}$ & $\begin{array}{l}\text { Masyarakat Melakukan } \\
\text { proses Produksi secara } \\
\text { manual }\end{array}$ & $\begin{array}{l}\text { Masyarakat melakukan } \\
\text { produksi dengan } \\
\text { menggunakan teknologi } \\
\text { terbarukan dengan } \\
\text { percepatan proses } \\
\text { produksi }\end{array}$ \\
\hline 4 & Hasil produksi & $\begin{array}{l}\text { Masih dengan kapasitas } \\
\text { kecil dan mengalami } \\
\text { kesulitan dalam proses } \\
\text { pemasaran }\end{array}$ & $\begin{array}{l}\text { Hasil penjualan } \\
\text { meningkat yang disertai } \\
\text { dengan penjualan melalui } \\
\text { online. }\end{array}$ \\
\hline
\end{tabular}

\section{PENUTUP}

Proses pengeringan kopi dengan menggunakan pemanas oven dengan tujuan untuk mempercepat proses pengeringan kopi dengan menggunakan bahan bakar gas, briket dan kayu. Dengan penerapan teknologi mesin pengering kopi, proses produksi kopi semakin lebih cepat dan efisien. Sehingga hasil produksi meningkat dan kesejahteraan masyarakat juga meningkat. Teknologi pada mesin pengering kopi perlu ditingkatkan kembali, untuk menghasilkan sistem kerja dari mesin yang lebih maksimal.

\section{DAFTAR PUSTAKA}

Abdul Rachman, Arifin. (2001). Administrasi Pemerintahan Dalam Pembangunan, CV. Haji Mas Agung. Jakarta.
Abdul rachman, S., A. Karim, M., I. Las, and I. Juliadi, 2006. Integrated crop management experiences on lowland rice in Indonesia, In Sumarno,Suparyo, A.M.Fagi and M.O. Adnyana (eds). Rice industri, culture and enviroment, Book 1. Indonesian Center for Rice Researh, Sukamandi.

Besari, M.S, "Teknologi di Nusantara", Salemba Teknika, Jakarta, 2008.

http://tirtoyudo.malangkab.go.id/. Diakses Pada Tanggal 20 Agustus 2019.

Rintuh, Cornelis dan Miar. (2005) Kelembagaan dan Ekonomi Rakyat. Yogyakarta. BPFE.

Suryana. (2006) Ekonomi Pembangunan: Problematika dan Pendekatan. Jakarta.

Tilaar, M.A.R, "Mengindonesia : Etnisitas dan Identitas Bangsa Indonesia", Rineka Cipta, Jakarta, 2007. 
DOI: https://doi.org/10.21009/sarwahita.162.09

P-ISSN: 0216-7484

E-ISSN: 2597-8926

Undang-Undang Republik Indonesia

ekonomi pola usaha tani. Nusa Nomor6 Tahun 2014 Tentang Desa, Jakarta: DPR

http// wikepdia, perkembangan desa sektor ekonomi, html.01-11-2014.

Van Der Veen, M.G. dan C.M. Gonzales. 1997. Latihan penelitian sosial-

Tenggara Agricultural Support

Project. Badan Penelitian dan

Pengembangan Pertanian bekerjasama dengan Agricultural Economics Departement International Rice Research Institute. Bahan Latihan Vol.1 